\title{
Интеркалирование натрием графеновых пленок на $\operatorname{Re}(10 \overline{10})$
}

\author{
(C) Е.В. Рутьков ${ }^{1}$, Е.Ю. Афранасьева ${ }^{1, \uparrow}$, Н.П. Лавровская ${ }^{2}$, Н.Р. Галль ${ }^{1}$ \\ ${ }^{1}$ Физико-технический институт им. А.Ф. Иофрфе РАН, \\ Санкт-Петербург, Россия \\ ${ }^{2}$ Государственный университет аэрокосмического приборостроения, \\ Санкт-Петербург, Россия \\ ฯ E-mail: afanaseva@ms.ioffe.ru
}

(Поступила в Редакцию 1 ноября 2017 г.)

Показано, что при низкотемпературном (300-500 К) интеркалировании тонких многослойных пленок графена и графита на рении атомами $\mathrm{Na}$ первый слой графена выступает в качестве ловушки, куда диффундируют через графитовую пленку поступающие на поверхность атомы. При концентрации атомов Na под первым слоем графена, приближающейся к максимально возможной $(2 \pm 0.5) \cdot 10^{14} \mathrm{~cm}^{-2}$, активно заполняется фаза интеркаляции межслоевого пространства в объеме графита. Емкость этой фазы пропорциональна толщине пленки графита, которая в работе могла изменяться от одного слоя графена до $\sim 50$ атомных слоев. Оценена энергия диффузии $E_{d}$ атомов Nа через пленку графита $E_{d} \approx 1.4 \mathrm{eV}$.

DOI: 10.21883/FTT.2018.05.45807.301

\section{1. Введение}

Открытый в наших работах [1,2] эффект интеркалирования графеновой пленки на металлах чужеродными атомами и молекулами, приводящий к самопроизвольному накоплению атомов (молекул) в пространстве между графеном и металлом, широко применяется в научном мире [3-6]. В частности, в настоящее время одной из важных задач является создание под пленкой графена на металле диэлектрического слоя путем интеркалирования атомов с последующим их окислением [7-11]. Закономерности интеркалирования графена на металлах атомами $\mathrm{Cs}, \mathrm{K}, \mathrm{Na}, \mathrm{Al}, \mathrm{Cu}, \mathrm{Ir}, \mathrm{Si}, \mathrm{Pt}$ и др., а также молекулами $\mathrm{C}_{60}$ представлены в нашей обобщающей работе [12], причем было показано, что именно потенциал ионизации является важнейшей характеристикой, описывающей закономерности этого процесса.

Если закономерности интеркалирования однослойного графена на металле и наоборот, объемного графита можно считать хорошо изученными [12,13], то переход от одного слоя графена к многослойным графеновым и графитовым пленкам совершенно не изучен, хотя такие пленки с толщиной в несколько слоев графена обладают рядом уникальных свойств [14-17].

В настоящей работе толщина пленки могла плавно изменяться от одного слоя графена до $~ 50$ атомных слоев. Целью настоящей работы было исследование процессов интеркалирования многослойных пленок графена и графита атомами щелочного металла - натрия, обладающего высокой диффузионной подвижностью и низким потенциалом ионизации.

\section{2. Методы и техника эксперимента}

Опыты проводились в условиях сверхвысокого вакуума $\left(P \approx 10^{-10}\right.$ Torr $)$ в призменном электрон- ном Оже-спектрометре высокого разрешения $(\Delta E / E \approx$ $\approx 0.1 \%$ ) [18]. В приборе имелся специальный модуль для применения метода ТЭПИ: термоэлектронной эмиссии и поверхностной ионизации зондирующих поверхность атомов и молекул $\mathrm{CsCl}$ - метод, разработанный нами для определения относительной площади графеновых островков на металле и качества (сплошности) таких пленок [19].

Образцами служили тонкие текстурированные рениевые ленты, имеющие размеры $50 \times 1 \times 0.02 \mathrm{~mm}$, однородные по работе выхода с гранью (1010) на поверхности с $e \varphi=5.15 \mathrm{eV}$. Очистка лент от примесей и выведение грани на поверхность были стандартными [20]. По данным рентгеновской дифракции степень ориентации грани (1010) по отношению к поверхности образца составляла $99.9 \%$. Лента нагревалась пропусканием тока, ее центральная часть длиной $40 \mathrm{~mm}$ была однородной по температуре с точностью $\pm 5 \mathrm{~K}$.

В работе применялся метод термодесорбционной спектроскопии (ТДС) в варианте, когда регистрируются слетающие с поверхности ионы $\mathrm{Na}^{+}$, полученные путем поверхностной ионизации [21], что существенно повышало чувствительность регистрации по отношению к регистрации десорбирующихся нейтральных атомов с последующей их ионизацией, например электронным ударом. Абсолютная калибровка потоков атомов $\mathrm{Na}$ требует полного сбора десорбирующихся ионов $\mathrm{Na}^{+}$и знания работы выхода поверхности, что имело место в данной работе. Ток ионов $\mathrm{Na}^{+}$, десорбирующихся с поверхности, определяется формулой Саха-Ленгмюра [21]:

$$
I_{\mathrm{Na}^{+}}=\frac{e \nu s}{1+A \exp \left(\frac{e(V-\varphi)}{k T}\right)},
$$

где $e-$ заряд электрона, $v-$ плотность потока частиц $\left(\mathrm{cm}^{-2} \mathrm{~s}^{-1}\right), s-$ площадь эмиттирующей поверхности (в данной работе $s=5 \mathrm{~mm}^{2}$ ), $A$ - отношение статсумм 
атомного и ионного состояний ионизирующихся атомов, $V$ - потенциал ионизации натрия $(V=5.21 \mathrm{eV}), e \varphi-$ работа выхода поверхности.

Взаимодействию углерода с рением посвящено много работ $[19,20,22]$. Для образования графеновой пленки на рении использовали крекинг паров бензола на нагретом до $T_{p}$ металле. При $T_{p}=1650-1750 \mathrm{~K}$ и $\mathrm{P}\left(\mathrm{C}_{6} \mathrm{H}_{6}\right) \approx 1 \cdot 10^{-5}$ Torr рениевый ленточный образец насыщался углеродом в течение 20-30 min. После достижения концентрации углерода в объеме, соответствующей предельной, на поверхности происходил двумерный фазовый переход с образованием островков графена, которые росли по площади, сливались, и на поверхности формировался только один сплошной слой графена. Данный факт подтверждался нашими многочисленными опытами, в том числе с применением метода ЭОС и метода СТМ [23,24]. На графене диссоциация бензола прекращалась и рост пленки по толщине сверх одного слоя не происходил. Средняя температура науглероживания $T_{p}=1650-1750 \mathrm{~K}$ позволяла сохранять один слой графена длительное время при снижении температуры вплоть до комнатной из-за относительно малой концентрации растворенных в объеме рения атомов углерода и из-за затрудненной диффузии атомов углерода в объеме образца. По той же причине крайне затруднительно науглеродить рений при $T_{p}<1600 \mathrm{~K}$ [19].

Для образования многослойных графеновых (графитовых) пленок температуру науглероживания повышали до $T_{p}=1900-2000 \mathrm{~K}$, что существенно увеличивало концентрацию растворенных в рении атомов углерода и их подвижность в объеме металла. Процесс науглероживания и в этом случае заканчивался образованием только одного слоя графена, но снижение температуры до $T=1300-1700 \mathrm{~K}$ приводило теперь к росту многослойных графеновых пленок.

Кинетика и механизм роста таких пленок рассмотрен в нашей работе [25]. Рост тонких графитовых пленок можно легко остановить снижая температуру до $T \leq 1200$ К. При таких температурах можно считать, что процессы диффузии атомов углерода по объему рения заморожены.

В работе [25] показано, что время образования $m$-ого слоя графена на рении связано со временем $t_{1}$ роста первого слоя простым соотношением $t=t_{1} m^{2}-$ лимитирующим фактором в кинетике роста пленки является доставка атомов углерода из объема к поверхности образца. Например, если первый слой графена при $T=1600 \mathrm{~K}$ вырастает быстро (секунды), то для образования $\sim 50$ слоев при той же температуре требуется время более трех часов.

Таким образом, система рений-углерод позволяет контролируемо образовывать графеновые пленки толщиной от одного слоя до $\sim 50$ слоев, при этом толщина пленки остается неизменной в диапазоне температур 300-1200 К. Кроме того, данные пленки легко полностью очистить от напыляемых веществ простым прогревом до $T \geq T_{p}+100 \mathrm{~K}$. При этом графеновая пленка разрушается, углерод растворяется в объеме подложки, а напыленные примесные атомы термически десорбируются. Для образования новой, чистой пленки графена требуется простое снижение температуры до $T=T_{p}$ (один слой графена) или $T<T_{p}$ (многослойная пленка).

\section{3. Результаты и их обсуждение}

В наших работах [2,12] показано, что атомы щелочных металлов $(\mathrm{Na}, \mathrm{K}, \mathrm{Cs})$ в области температур $T=300-600 \mathrm{~K}$ интеркалируют графеновые пленки на разных металлах: $\operatorname{Ir}(111), \mathrm{Ni}(111), \mathrm{Rh}(111), \mathrm{Mo}(100)$, $\operatorname{Re}(10 \overline{1} 0)$ - до субмонослойных покрытий. При этом в спектрах термодесорбции всегда наблюдаются две фазы десорбции, разделенные по температуре: низкотемпературная фаза $(\sim 700-800 \mathrm{~K})$, связанная с десорбцией атомов с поверхности графена, и более высокотемпературная фаза, связанная с выходом интеркалята из-под графеновой пленки с последующей десорбцией. Отметим, что если для удаления „больших“ атомов Cs, находящихся под слоем графена на $\operatorname{Re}(10 \overline{1} 0)$, требуется температура $T>2000 \mathrm{~K}$ и полное разрушение графена, то „меньшие“ атомы К десорбируются из-под графена до его разрушения. Размер атомов $\mathrm{Na}$ существенно меньше атомов $\mathrm{K}$, и тем более у Cs, и можно ожидать выхода атомов натрия из-под графена при гораздо более низких температурах. Интересно отметить, что если интеркалированные атомы Cs дополнительно увеличивают межплоскостное расстояние в графите на $2.59 \AA$, калий на $2.0 \AA$, то Nа увеличивает это расстояние на $1.2 \AA$ [13].

На рис. 1, $a$ представлен спектр термодесорбции после адсорбции атомов Na при $T=500 \mathrm{~K}$ на пленку графита толщиной $m \approx 50$ слоев, при этом температурная „вспышка“ производилась сразу же после напыления. Первая фаза с температурным максимумом $\sim 1000 \mathrm{~K}$, связывается нами с выходом интеркалированных атомов $\mathrm{Na}$ из объема графитовой пленки - как следует из дальнейших опытов адсорбционная емкость этой фазы растет практически неограниченно - зависит от толщины (объема) графитовой пленки.

Вторая фаза полностью совпадает с фазой, соответствующей интеркалированным атомам $\mathrm{Na}$ для случая одного слоя графена. На первый взгляд немного удивительно - откуда берется эта фаза при напылении атомов $\mathrm{Na}$ поверх графитовой пленки с $m \approx 50$ слоев. Можно предположить, что при $T=500 \mathrm{~K}$ атомы $\mathrm{Na}$ начинают интеркалировать объем графита уже во время напыления адсорбата. Подъем температуры приводит к разделению интеркалированного натрия: часть адсорбата диффундирует к поверхности и затем десорбируется (фаза 1 на рис. $1, a)$, другая часть диффундирует от поверхности ко дну пленки до первого графенового слоя и уже потом при дальнейшем подъеме температуры дает фазу 2 (рис. 1,a). Если увеличивать концентрацию напыленного $\mathrm{Na}$, но не более чем $\sim 1 \cdot 10^{14} \mathrm{~cm}^{-2}$, то 
фазы 1 и 2 подрастают почти синхронно, одинаково. Если это так, то следующий опыт подтвердит наше предположение. Выдержим образец перед температурной „вспышкой“ некоторое время $t$, т.е. дадим возможность интеркалированным атомам $\mathrm{Na}$ в графите „стечь“ до дна пленки. На рис. $1, b$ и $c$ показана трансформация термодесорбционного спектра после отжига пленки графита с $\mathrm{Na} п р и ~ T=500 \mathrm{~K}$. Видно, что с увеличением $t$ фаза 1 существенно уменьшается и при $t>120 \mathrm{~s}$ практически исчезает. В то же время, фаза 2, наоборот, увеличивается. Таким образом, за
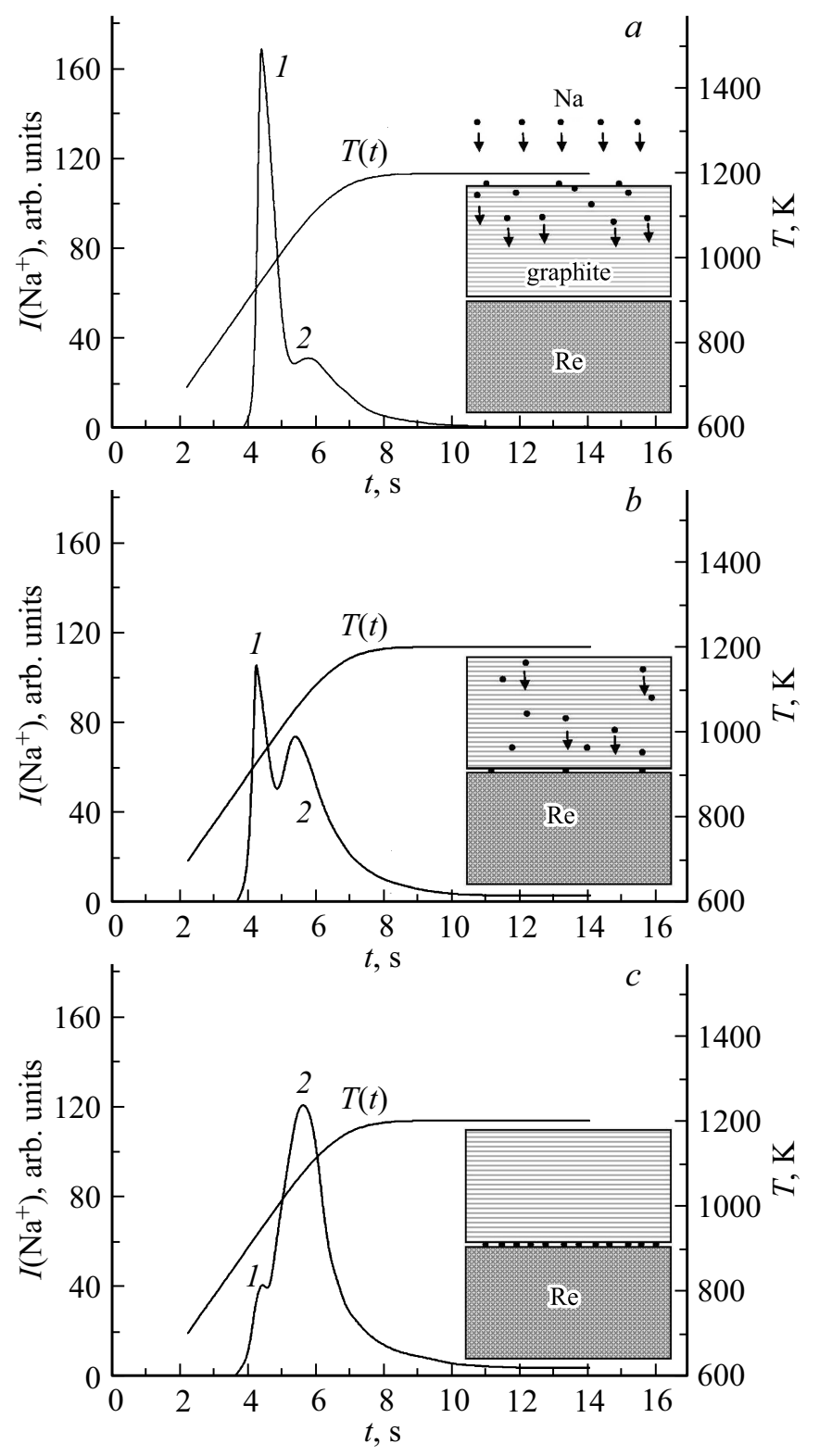

Рис. 1. Термодесорбционные спектры для $\mathrm{Na}$, адсорбированного на пленку графита толщиной $m \approx 50$ слоев на $\operatorname{Re}(10 \overline{1} 0)$ при $T_{a}=500 \mathrm{~K}$ дозой $N_{0}=v t \approx 5 \cdot 10^{13} \mathrm{~cm}^{-2}$ с последующим отжигом при $T=500 \mathrm{~K}$ в течение времени $t, \mathrm{~s}: a-0 ; b-30$; $c-120$. Справа - упрощенные иллюстрации к процессу интеркалирования пленки.

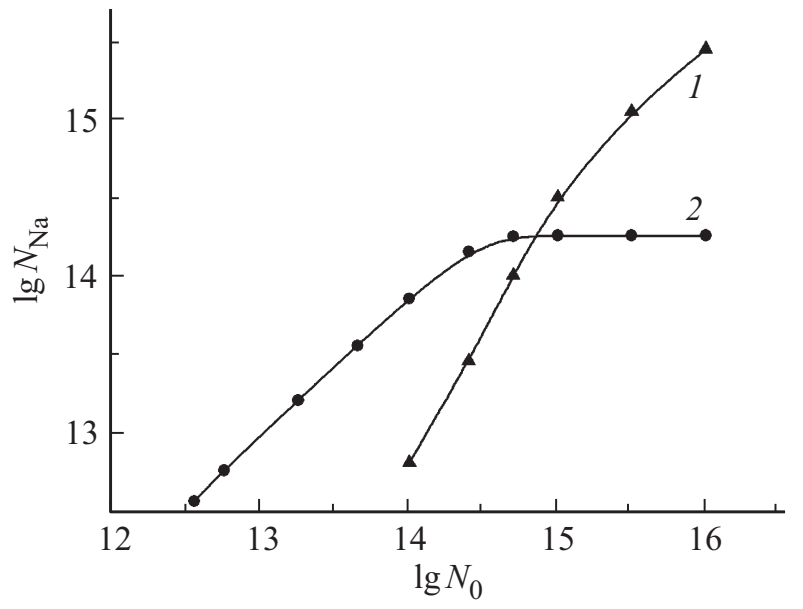

Рис. 2. Зависимость концентрации атомов $\mathrm{Na}$ в координатах $\lg \left(N_{\mathrm{Na}}\right)$ в объеме графитовой пленки $(1)$ и под первым слоем графена (2) от дозы поступивших на поверхность пленки графита $(m \approx 50)$ атомов $\mathrm{Na}$ при $T_{a}=500 \mathrm{~K}$ в координатах $\lg \left(N_{0}\right)$, где $N_{0}=v t, v-$ плотность потока атомов.

время $t \approx 120 \mathrm{~s}$ весь интеркалированный натрий „собрался“ на дно пленки, т.е. оказался между первым слоем графена и металлом (рис. 1,c). Попробуем оценить энергию диффузии атомов Na по объему графитовой пленки. Действительно, толщина пленки $x$ равна $x=m \cdot 3.35 \AA=1.7 \cdot 10^{-6} \mathrm{~cm}$. С учетом известного выражения для объемной диффузии $x=\sqrt{2 D_{0} t \exp \left(-\frac{E}{k T}\right)}$, где положим $D_{0} \approx\left(10^{-1}-10^{-2}\right) \mathrm{cm}^{2} \mathrm{~s}^{-1}$ [26], с учетом $T=500 \mathrm{~K}$ и $t \approx 100 \mathrm{~s}$, получим $E \approx 1.4 \mathrm{eV}$, что кажется весьма разумным.

На рис. 2 представлены графики зависимости концентрации атомов $\mathrm{Na}$ в фазах 1 и $2\left(\lg \left(N_{1}\right)\right.$ и $\lg \left(N_{2}\right)$ соответственно) от дозы поступивших на поверхность пленки графита при $T=500 \mathrm{~K}$ атомов натрия в координатах $\lg \left(N_{0}\right)$, где $N_{0}=v t$, а $v$ - плотность потока атомов Na. Перед температурной „вспышкой“ образец выдерживали $t=120 \mathrm{~s}$ при $T=500 \mathrm{~K}$. Видно, что сначала адсорбат накапливается в фазе 2 (кривая 2), соответствующей первому слою графена. При приближении концентрации в этой фазе к максимально возможной $N_{2}=(2 \pm 0.5) \cdot 10^{14} \mathrm{~cm}^{-2}$ начинает заполняться фаза 1 (кривая 1), т. е. натрий накапливается в интеркалированном состоянии в объеме графита. Как уже говорилось выше, адсорбционная емкость этой фазы определяется толщиной (объемом) графитовой пленки.

Из опытов по стеканию и существенному накоплению атомов $\mathrm{Na}$ под первым слоем графена следует, что энергия $E_{1}$ активации перехода атомов из первого слоя во второй гораздо больше, чем внутренние переходы атомов $\mathrm{Na}$ из слоя в слой в объемном графите: $E_{2} \approx 1.4 \mathrm{eV}$. Попробуем оценить разность равновесных концентраций адатомов $\mathrm{Na}$ под первым слоем графена $N_{1}$ и, например, во втором слое графена $N_{2}$. Используя известные выражения для равновесных пото- 

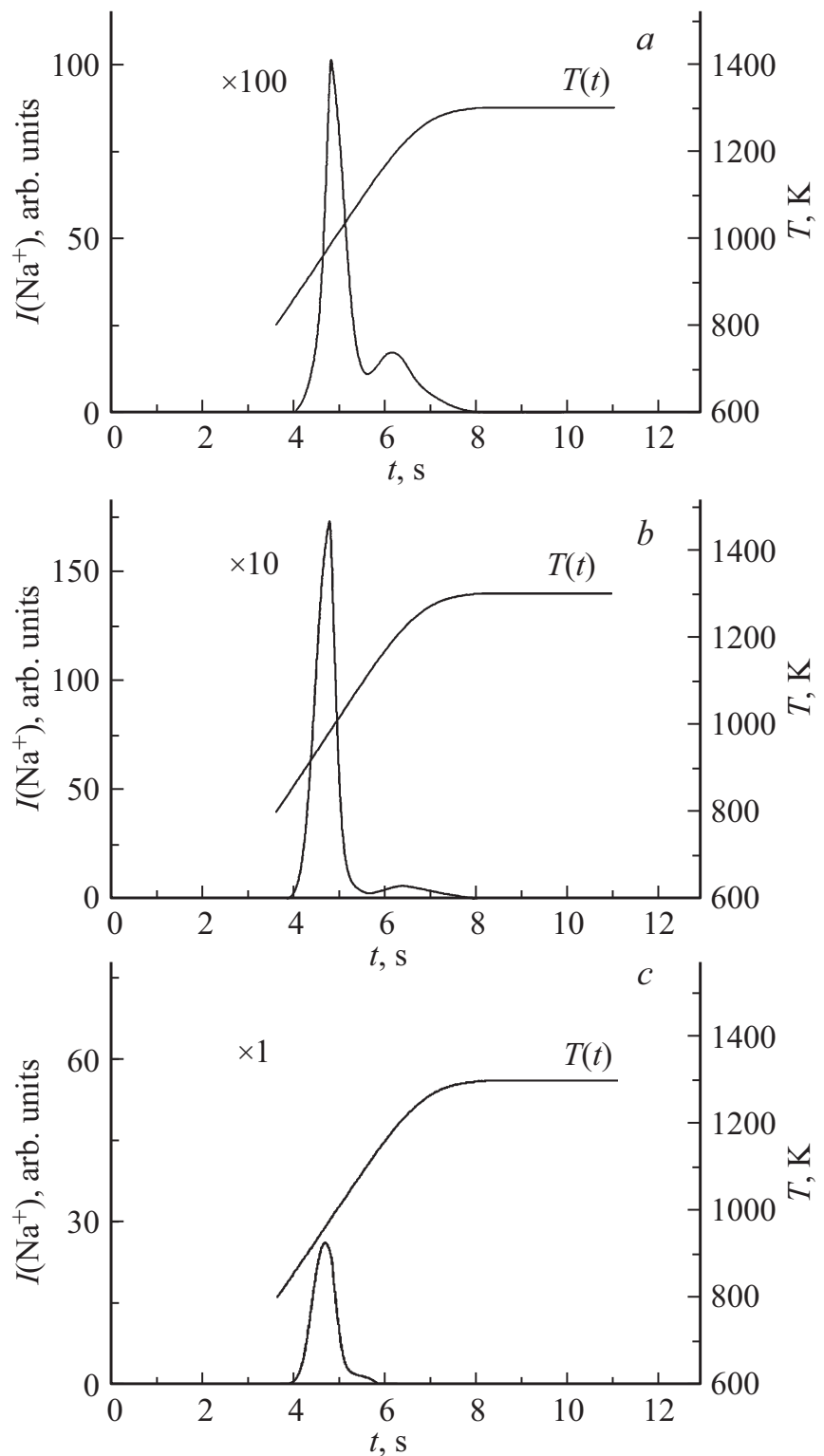

Рис. 3. Термодесорбционные спектры для $\mathrm{Na}$, адсорбированного на пленку графита $(m \approx 20)$ при $T_{a}=500 \mathrm{~K}$ в случае больших доз $N_{0}=v t, \mathrm{~cm}^{-2}: a-2.7 \cdot 10^{15} ; b-4 \cdot 10^{16}$; $c-6.4 \cdot 10^{16}$.

ков $v_{1}=N_{1} C \exp \left(-E_{1} / k T\right)$ и $v_{2}=N_{2} D \exp \left(-E_{2} / k T\right)$ [27] и считая в первом приближении равенство предэкспоненциальных множителей $C \approx D$, получим, что $N_{1} / N_{2}=\exp \left(\left(E_{2}-E_{1}\right) / k T\right)=\exp (\Delta E / k T)$. В наших опытах $T=500 \mathrm{~K}, E_{2}=1.4 \mathrm{eV}$ и, если $E_{1}$ близка к энергии связи атомов $\mathrm{Na} \mathrm{с} \mathrm{металлом} E_{1} \approx 3 \mathrm{eV}$ [19], то $N_{1} / N_{2} \approx 10^{13}$.

Нетрудно подсчитать, что даже небольшое отличие между $E_{1}$ и $E_{2}$, например на $20 \%$, дает разность между $N_{1}$ и $N_{2}$ на четыре порядка величины. Поэтому первый слой графена на металле и выступает в качестве адсорбционной (интеркаляционной) ловушки для поступающих на поверхность тонких графеновых пленок чужеродных атомов. По мере накопления атомов $\mathrm{Na}$ под первым слоем уменьшается энергия связи их с металлом, и в предельном случае концентрации атомов $\mathrm{Na}$ в любом слое графита становятся соизмеримыми с таковой для первого слоя графена [13]. Для атомов с большими потенциалами ионизации, а таких большинство, можно ожидать, что $E_{1} \gg E_{2}$. Действительно, если атомы $\mathrm{Cu}$ и $\mathrm{Au}$, например, лишь физадсорбируются на графите, то с тугоплавкими металлами их связь составляет несколько электрон-вольт [28].

На рис. 3 показаны термодесорбционные спектры для атомов $\mathrm{Na}$ при больших напыленных дозах $N_{0}=v t>2 \cdot 10^{15} \mathrm{~cm}^{-2}$. Видно, что теперь рост первой фазы заметно опережает рост второй фазы, которая имеет ограничения по адсорбционной емкости. При $N_{0}>4 \cdot 10^{16} \mathrm{~cm}^{-2}$ практически наблюдается только первая фаза десорбции, так как $N_{1} \gg N_{2}$ (рис. $\left.3, c\right)$.

Отметим также, что небольшая доля интеркалированных атомов $\mathrm{Na}$ под первым слоем графена при нагреве подложки растворяется в объеме рения, хотя без графена растворить атомы $\mathrm{Na}$ прямым напылением не удается ни при таких температурах — атом $\mathrm{Na}$ предпочитает десорбироваться нежели диффундировать в объем металла. При многократных повторных опытах, описанных выше, количество растворенных в металле атомов $\mathrm{Na}$ растет, и для полной очистки образца от натрия необходим прогрев ленты до $T \geq 2200 \mathrm{~K}$. Эффект принудительного растворения в металле интеркалированных атомов за счет графеновой „крыши“ наблюдался неоднократно для разных систем металл-графен и связан, прежде всего, с существенным температурным сдвигом начала десорбции интеркалированных атомов, „запертых“ под слоем графена. Например, в случае Cs на графене на $\operatorname{Re}(1010)$ этот сдвиг составляет более $1000 \mathrm{~K}$, что открывает канал растворения в металле атомов Cs [12].

\section{4. Заключение}

Таким образом, первый слой графена в графитовой пленке на рении выступает в качестве ловушки (накопителя) для поступающих на поверхность атомов $\mathrm{Na}$, поскольку у адатомов химическая связь с металлом гораздо сильнее, чем с поверхностью графенового слоя в объеме графита. Можно ожидать, что представленные результаты демонстрируют общую закономерность, характерную и для других атомов при интеркалировании тонких многослойных графитовых пленок на металлах: способность первого слоя графена, прилегающего к металлу, проявить себя как накопителя интеркалирующих атомов. Графеновая „крыша“ первого слоя, удерживая интеркалированные атомы между металлом и графеном, открывает при нагреве системы канал растворения этих атомов в объеме металла, отсутствующий в случае свободной поверхности. 


\section{Список литературы}

[1] Е.В. Рутьков, А.Я. Тонтегоде. Письма в ЖТФ 7, 1122 (1981).

[2] Е.В. Рутьков, А.Я. Тонтегоде. УФН 163, 57 (1993).

[3] R. Larciprete, S. Ulstrup, P. Lacovig, M. Dalmiglio, M. Bianchi, F. Mazzola, L. Hornekar, F. Orlando, A. Baraldi, P. Hofmann, S. Lizzit. ASC Nano 6, 9551 (2012).

[4] E. Grånäs, M. Andersen, M.A. Arman, T. Gerber, B. Hammer, J. Schnadt, J.N. Andersen, T. Michely, J. Knudsen. J. Phys. Chem. C 117, 16438 (2013).

[5] I.I. Klimovskikh, O. Vilkov, D.Yu. Usachov, A.G. Rybkin, S.S. Tsirkin, M.V. Filianina, K. Bokai, E.V. Chulkov, A.M. Shikin. Phys. Rev. B 92, 165402 (2015).

[6] G.S. Grebenyuk, O.Y. Vilkov, A.G. Rybkin, M.V. Gomoyunova, B.V. Senkovskiy, D.Y. Usachov, D.V. Vyalikh, S.L. Molodtsov, I.I. Pronin. Appl. Surf. Sci. 392, 715 (2017).

[7] E.N. Voloshina, A. Generalov, M. Weser, S. Böttcher, K. Horn, Y.S. Dedkov. New J. Phys. 13, 113028 (2011).

[8] S. Lizzit, R. Larciprete, P. Lacovig, M. Dalmiglio, F. Orlando, A. Baraldi, L. Gammelgaard, L. Barreto, M. Bianchi, E. Perkins, P. Hofmann. Nano Lett. 12, 4503 (2012).

[9] Е.Ю. Афанасьева, Е.В. Рутьков, Н.Р. Галль. Письма ЖТФ 42, 11, 64 (2016).

[10] A. Dahal, M. Batzill. Sci. Rep. 5, 11378 (2015).

[11] J. Park, T. Back, S.B. Fairchild, W.C. Mitchel, S. Elhamri, J. Boeckl, D. Martinotti, L. Douillard, P. Soukiassian. Carbon 116, 303 (2017).

[12] N.R. Gall, E.V. Rut'kov. In: Physics and Applications of Graphene-Experiments / Ed. S. Mikhailov. Intech Open Access Publ., Rijeca-L., (2011). P. 293-326.

[13] M.S. Dresselhaus, G. Dresselhaus. Adv. Phys. 30, 139 (1981).

[14] К.С. Новоселов. УФН 181, 1299 (2011).

[15] P.H. Tan, W.P. Han, W.J. Zhao, Z.H. Wu, K. Chang, H. Wang, Y.F. Wang, N. Bonini, N. Marzari, N. Pugno, G. Savini, A. Lombardo, A.C. Ferrari. Nature Mater. 11, 294 (2012).

[16] J. Nilsson, A.H. Castro Neto, F. Guinea, N.M.R. Peres. Phys. Rev. Lett. 97, 266801 (2006).

[17] K.F. Mak, M.Y. Sfeir, J.A. Misewich, T.F. Heinz. PNAS 107, 34, 14999 (2010).

[18] N.R. Gall, E.V. Rut'kov, A.Ya. Tontegode. Int. J. Mod. Phys. B11, 1865 (1997).

[19] N.R. Gall, E.V. Rut'kov. In: Physics and Applications of Graphene-Experiments / Ed. S. Mikhailov. Intech Open Access Publ., Rijeca-L. (2011). P. 209-292.

[20] N.R. Gall, S.N. Mikhailov, E.V. Rut'kov, A.Ya. Tontegode. Surf. Sci. 191, 185 (1987).

[21] Э.Я. Зандберг, Н.И. Ионов. Поверхностная ионизация. Наука, М. (1969). 432 с.

[22] E. Miniussi, M. Pozzo, T.O. Mentes, M.A. Niño, A. Locatelli, E. Vesselli, G. Comelli, S. Lizzit, D. Alfè, A. Baraldi. Carbon 73, 389 (2014).

[23] Z. Waqar, I.V. Makarenko, A.N. Titkov, N.R. Gall, E.V. Rut'kov, A.Ya. Tontegode. J. Mater. Res. (JMR) 19, 1058 (2004).

[24] 3. Вакар, Н.Р. Галль, И.В. Макаренко, Е.В. Рутьков, А.Н. Титков, А.Я. Тонтегоде, М.М. Усуфов. ФТТ 40, 1570 (1998).

[25] Е.В. Рутьков, Н.Р. Галль, Н.Д. Потехина. ФТТ 56, 1645 (2014).

[26] Дж. Андерсон. Структура металлических катализаторов. Мир, М. (1978). 482 с.

[27] A.Ya. Tontegode. Prog. Surf. Sci. 38, 201 (1991).

[28] J.R. Arthur, A.Y. Cho. Surf. Sci. 36, 642 (1973). 